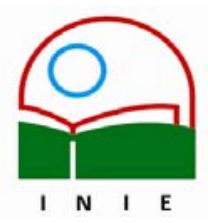

Universidad de Costa Rica

Facultad de Educación

Instituto de Investigación en Educación

ACTUALIDADES INVESTIGATIVAS EN EDUCACION

\title{
LA DISCIPLINA EN EL AULA: REFLEXIONES EN TORNO A LOS PROCESOS DE COMUNICACIÓN
}

\author{
Carmen María Cubero Venegas ${ }^{1}$
}

Resumen: La disciplina en el aula es un aspecto de la educación de los alumnos que ha preocupado siempre a los educadores, así como a los padres y madres. Por esta razón, un equipo interdisciplinario de investigadoras de la Universidad de Costa Rica, propuso realizar una investigación sobre la percepción y el manejo de la disciplina en el aula, con el fin de conocer esa realidad cotidiana en que se encuentran el alumno y el docente.

La descripción de lo que sucede en el aula, recopilada y discutida desde la perspectiva de la orientación, la educación especial y la psicología educativa, permitió que ese acercamiento reflejara la necesidad de un ambiente escolar, donde todos los participantes trabajen en forma armoniosa, tanto para que el docente pueda desarrollarse como profesional, como para que los alumnos desempeñen las acciones y actividades naturales y propias de su edad. La comunicación, es uno de los aspectos que tienen mayor influencia en la dinámica del aula y en este artículo se pretende aplicar la propuesta de S. Walroos en su libro "La comunicación en la familia. Una guía hacia la salud emocional", a la realidad de la vida cotidiana de los docentes en las aulas. La oportunidad de compartir horas de observación en las aulas con una maestra y un maestro, facilitó conocer patrones de comunicación encontrados que se acercan con bastante certidumbre a estilos propios de la dinámica docente y a la necesidad de hacerlos conscientes, sea para fortalecerlos o para corregirlos.

Palabras clave: DISCIPLINA/ COMUNICACIÓN/ COMUNICACIÓN EN EL AULA/ DOCENCIA Y COMUNICACIÓN/ RELACIONES INTERPERSONALES EN EL AULA/ SALUD MENTAL/ SALUD EMOCIONAL

Abstract: Discipline within the classroom is an aspect of schoolchildren's education that has always worried teachers, as well as parents. For this reason, an interdisciplinary team of researchers in the Universidad de Costa Rica made a proposal to carry out a research project that deals with the perception and handling of discipline in the classroom, with the purpose of experiencing the daily reality where teacher and student meet. The description of what happens within the classroom, compiled and discussed from the perspective of orientation, special education and educative psychology, allowed this close examination to show the need for a school environment, where all actors work harmoniously; so that the teacher may develop as a professional, and for the students to perform the actions and natural activities according to their ages. Communication is one of the aspects of greater influence in the classroom's dynamics; in this article we intend to apply S. Walroos's proposal in his book "Family Communication. A guide to emotional health", to the teachers' daily life situation within the classroom. The opportunity of sharing hours of observation in the classroom with a female and a male teacher made easier to understand those communication patterns that approached with acceptable certainty the proper styles in teaching dynamics, and to understand the need to become aware of them, to strengthen them or to correct them.

Key words: DISCIPLINE/ COMMUNICATION/ COMMUNICATION INSIDE THE CLASSROOM/ TEACHING AND COMMUNICATION/INTERPERSONAL RELATIONS IN THE CLASSROOM/MENTAL HEALTH/ EMOTIONAL HEALTH/

\section{Importancia de la disciplina escolar}

En la literatura se reseña que muchos educadores estiman que su incapacidad para manejar la disciplina les impide disfrutar el ejercicio de su profesión, al elaborar sentimientos de frustración e ineptitud. Esta situación no solo es frustrante para el docente como ser

\footnotetext{
${ }^{1}$ Licenciada en Psicología de la Universidad de Costa Rica. Profesora de Enseñanza Media de Universidad de Costa Rica. Estudios de Maestría en Administración Pública en el Instituto Centroamericano de Administración Pública. Profesora de la Escuela de Orientación y Educación Especial, Sección de Psicopedagogía de la Universidad de Costa Rica. Coordinadora del Programa para el Mejoramiento de los Procesos de la Enseñanza y Aprendizaje del Instituto de Investigación en Educación. Correo electrónico: ccubero@cariari.ucr.ac.cr
}

Artículo recibido: 17 de setiembre, 2004

Aprobado: 13 de diciembre. 2004 
humano, sino que ocasiona situaciones de tensión en el aula o, bien, el abandono que hace de la docencia y de la inversión económica que ha hecho para formarse.

Si se revisa con una perspectiva histórica, el concepto de disciplina es muy dinámico. En él se pueden perfilar los valores e intenciones de la sociedad en el campo educativo. La concepción de hombre y de niño se evidencia claramente en los lineamentos sobre la disciplina, tanto en el hogar, como en la escuela y la comunidad. Stenhouse (1974, p. 24), manifiesta refiriéndose a este concepto:

Dondequiera que grandes cantidades de personas se reúnen para vivir y trabajar en grupos, son imprescindibles ciertas normas para regular su comportamiento y asegurar un elemental orden social. Esto es especialmente válido en la escuela, y la responsabilidad final de alcanzar ese orden recae en el personal docente...

Por su parte Howard (citado por Yelon y Weinstein, 1988, p. 390) afirma que la disciplina es indispensable para que un grupo y los individuos puedan funcionar:

... la buena disciplina es importante porque ningún grupo de gente puede trabajar en conjunto, exitosamente, sin establecer normas o reglas de conducta, respeto mutuo y un sistema conveniente de valores que oriente a cada persona del grupo a desarrollar autocontrol y autodirección.

La escuela como institución de orden social, no es ajena a este pensamiento y, por eso, la disciplina ha sido un área de estudio, discusión y búsqueda de enfoques que faciliten la convivencia y el fomento de la buena salud mental de los docentes y de los alumnos.

La escuela generalmente tiene un conjunto de normas explícitas e implícitas que regulan la actividad y las interrelaciones de los miembros de la comunidad que la componen. En estas normas podemos observar varias tendencias, entre ellas, la seguridad personal de niños, adolescentes y adultos en clase y recreos, y la posibilidad de trabajar en un ambiente que favorezca el aprendizaje. Tanto las normas implícitas como las explícitas pueden ser transgredidas y, el resultado de esto produce un ambiente caótico donde es casi imposible enseñar y aprender, y en donde las relaciones humanas se violentan.

Estudios realizados en los Estados Unidos y en Costa Rica, ponen de manifiesto que la disciplina es uno de los aspectos de mayor preocupación para los directores de las escuelas, 
los docentes, los padres y madres de familia y aún los mismos estudiantes. Como lo señalan la Revista "Phi, Delta Kappa", (1977); Curwin y Mendler, (1983); García, Rojas y Brenes (1994), entre otros.

La búsqueda de una disciplina adecuada y la importancia de ésta, radican prioritariamente en el hecho de que es:

imprescindible que exista, para que la organización del aula y de toda la escuela, facilite los procesos de socialización y enseñanza-aprendizaje, que no pueden realizarse en ambientes educativos carentes de normas que garanticen la posibilidad de que se lleven a cabo esos procesos en la forma más eficiente posible. (Cubero, Abarca y Nieto, 1996, p. 9)

Las causas de la indisciplina de los estudiantes, no se encuentran únicamente en la escuela, según Edwards (1993), éstas se pueden ubicar en cinco niveles, tales como: el hogar, la sociedad en sí misma, las condiciones escolares, los procedimientos administrativos de la escuela y el maestro.

En el presente articulo, no nos detendremos en un análisis exhaustivo de cada una de ellas; pero es necesario no perder de vista que lo referente a la disciplina es complejo y, por tanto, su tratamiento también debe requerir de mucha claridad y empeño en el medio educativo. Es imperioso dedicar tiempo a su atención.

Es necesario que el director y el equipo docente de una escuela, se preocupen por establecer un sistema disciplinario que proporcione seguridad, orden y respeto al maestro y a los alumnos. Las normas o reglas de conducta que se establezcan, deben basarse en un parámetro de conducta estándar, tal y como lo proponen Curwin y Mendler (1983), pues de esta manera, se facilita un entendimiento de los límites necesarios para que se atiendan las necesidades de los alumnos, del maestro, del grupo y de la comunidad educativa. Esta delimitación de lo permitido y lo no permitido en el aula o la escuela, proporciona mucha seguridad a los estudiantes, porque les dice en forma clara, lo que se espera y lo que no se espera de ellos y el por qué (Cubero, Abarca y Nieto, 1996).

Charles (1989), Watkins y Wagner (1991), Wielkiewicz (1992), García, Rojas y Brenes (1994), Cubero, Abarca y Nieto (1996), entre otros, coinciden en las características que 
deben poseer las reglas o normas para que su aplicación sea óptima. Entre ellas tenemos:

a) La importancia de que los estudiantes participen en la formulación de las normas de convivencia. Esto es necesario, pues de esta forma se construye la responsabilidad grupal e individual para su aplicación.

b) Las normas deben ser pocas, sencillas y claras de tal manera que todos los miembros del grupo las comprendan en todos sus alcances. La comunicación con un vocabulario adecuado en el nivel intelectual de los estudiantes, es un requisito indispensable.

c) Los alumnos deben estar muy claros y el maestro debe asegurarse de que todos han comprendido que la aplicación de las normas es para todos, incluido el maestro, pues estas normas deben ser para la convivencia.

d) Al establecer las normas, el maestro y el grupo deben estipular las consecuencias que se aplican, si las mismas son cumplidas, así como lo que va a suceder, si no se cumple con lo acordado. Además es muy importante que estas consecuencias queden establecidas desde el principio para que así se pueda ayudar a los niños a internalizarlas.

e) Las normas para que sean efectivas, deben aplicarse consistentemente, esto significa que siempre que se da una determinada situación, rigen las pautas acordadas, lo que le da solidez a la normativa y permite que las personas sepan cómo se espera que se comporten. Este aspecto es clave si se quiere trabajar en ayudar a los niños a establecer mecanismos de autocontrol. Cuando la norma no es consistente, se crea en el niño sentimientos de inseguridad, al no tener él mismo claro qué es lo que se espera que haga y cuándo una cosa es permitida y cuándo no.

f) Las normas deben ser congruentes con la situación, tanto si se trata de reconocer el cumplimiento de las mismas, como si se trata de aplicar una sanción por su trasgresión. Por esta razón, se deben establecer previamente las consecuencias, pues de esta forma, se evita el subjetivismo y el actuar bajo el influjo del enojo en el momento en que ocurre la transgresión.

g) Las normas o reglas deben revisarse periódicamente, no es conveniente que una conducta que se ha hecho rutina y que los niños han incorporado en su comportamiento, siga siendo objeto de trabajo en el aula. Es conveniente recordar que muchas de las conductas para la convivencia que tenemos los seres humanos han sido incorporadas y se realizan con naturalidad. Ese es el objetivo último de las normas de conducta, tanto en el aula como en el hogar. 


\section{Niveles de intervención en el aula}

Aunque se trabaje en el aula y en la escuela para establecer las normas de disciplina y, aún contando con el esfuerzo de los docentes y la buena voluntad de la mayoría de los alumnos, los problemas de disciplina siempre se van a presentar. Es por esto que Charles (1989), propone que existe una serie de técnicas a las cuales el docente puede recurrir, y las clasifica en tres tipos:
a) Técnicas preventivas
b) Técnicas de apoyo
c) Técnicas correctivas

Curwin y Mendler (1983, pp. 29-30), manifiestan que las técnicas de prevención en el manejo de la disciplina, buscan minimizar o prevenir que se presenten problemas en el aula y en la escuela. Cubero, Abarca y Nieto (1996), indican que hacer la lección atractiva, parece ser clave para prevenir la indisciplina, y el mantener la atención del grupo el mayor tiempo posible, es uno de los mejores recursos para prevenir el mal comportamiento.

Kounin (citado por Charles, 1989), recomienda que el docente debe cuidar el movimiento de la lección, el ritmo, la velocidad y las transiciones; para esto debe prestar atención a la forma cómo plantea las indicaciones las cuales deben ser claras y precisas. Es necesario finalizar un trabajo antes de iniciar otro y se debe emplear el tiempo necesario en las indicaciones y explicaciones de lo que se espera que sea el comportamiento y el trabajo suyo y de los alumnos.

Ginott (citado por Charles, 1989), propone que un medio para prevenir el mal comportamiento es utilizar siempre una comunicación congruente y razonable dirigida a la situación y, bajo ninguna circunstancia, se debe atacar la autoestima del alumno. En una comunicación congruente tanto el docente como el estudiante, pueden y deben expresar los sentimientos de manera respetuosa y transparente. La comunicación congruente evita el uso de los dobles mensajes - como expresar algo, cuando se quiere decir otra cosa- ya que confunde a las personas y puede promover la indisciplina.

Las técnicas de apoyo son muy útiles, cuando se inician las conductas perturbadoras que los alumnos presentan, tales como: conversar, caminar por el aula cuando se requiere que estén en sus pupitres, cuando molestan a los compañeros, etc. Por tales razones, el 
maestro debe utilizar estrategias de apoyo para que aquellos se comporten, como se necesita en ese momento.

El lenguaje corporal que puede utilizar el docente, entendido este como el contacto visual, la proximidad física, el desplazamiento por el aula, la expresión facial y los gestos, comunican a los alumnos mensajes que les pueden ayudar a autocontrolar su comportamiento.

El docente también puede aprender a captar las señales comunicativas que los alumnos envían por medio del lenguaje corporal, para facilitar la aplicación de estrategias metodológicas que le ayuden a prevenir la indisciplina.

El uso de la voz, tanto el tono como los diferentes matices, pueden comunicar a los alumnos lo que se espera de ellos. Lo recomendable es que no se tenga que recurrir al tono áspero o a los gritos, tampoco que la voz denote sarcasmo, burla o amenaza. Generalmente bajar el tono cuando los alumnos están perturbando la lección, tiene mejor resultado que subirlo y gritar para hacerse escuchar.

Las medidas de apoyo disciplinario en su gran mayoría no requieren la interrupción de la lección, sino que su aplicación se realiza mediante un código que han establecido los maestros con los alumnos; un ejemplo de esto es el mirar directamente al alumno que está conversando y bajar la voz para llamar su atención, o desplazarse por la clase, hasta al lugar donde los alumnos están perturbando la lección, sin necesidad de interrumpir lo que se está haciendo.

Por su parte, las técnicas correctivas se aplican en "situaciones en que resulta necesario utilizar... (recursos)... para que el alumno asuma las consecuencias por haber sobrepasado los límites que todo el grupo contribuyó a definir" (Cubero, Abarca y Nieto, 1996).

Algunas de las técnicas correctivas que funcionan muy bien con los estudiantes se relacionan con la atención del maestro; tal es el caso cuando se elogia y atiende al niño que cumple con la norma o, cuando solicita la palabra levantando la mano, y se explica al que la transgrede por qué es necesario que aplique esta disposición. La técnica de eliminar 
privilegios, es también un modo de ayudar al alumno a reconocer su mala conducta, siempre y cuando el docente destine espacios de reflexión que ayuden a los estudiantes a comprender la situación y que no se lesione la autoestima de ninguna de las personas involucradas.

\section{La docencia y la comunicación en el aula}

Para efectos del presente trabajo, la autora privilegia la información generada en la investigación citada, referente a la comunicación verbal y no verbal utilizada por los docentes. Los ejemplos con que se ilustran los diversos tipos de comunicación, son extraídos fielmente de las observaciones realizadas en el aula a una maestra y un maestro de quinto grado de dos escuelas públicas costarricenses.

La elección de este extracto de la investigación, obedece únicamente al interés de la autora de retomar la realidad encontrada en el aula en torno a la comunicación que utilizan los docentes, para compartirla con los lectores y aplicar la propuesta que hace Wahlroos (1978) sobre un modelo de comunicación familiar. Este modelo será adaptado desde la percepción personal de la autora, a la vida cotidiana del aula, por tanto será de su absoluta responsabilidad.

Se considera que la comunicación con los niños es básica para la construcción del concepto de sí mismo; es la vía por la cual, el niño crea ese concepto y comprende el valor que como persona tiene.

El sentir y pensar de los padres, madres y maestros respecto al niño (y también al adolescente y otras personas) se materializan en la comunicación. La primera comunicación es táctil: tocarse, mirarse a los ojos, acariciarse, entre otras cosas, ayuda a que el niño empiece a verse y sentirse persona. Sentirse reconocido por el entorno, es importante para la formación de la identidad personal, por lo que de la calidad de las relaciones primarias depende, en gran parte, cómo se percibe y considera a sí mismo el individuo posteriormente, y cómo mira el mundo que lo rodea.

Muy a menudo los adultos que conviven con los niños se preguntan ¿por qué, aunque se hayan tenido buenas intenciones, a veces los niños son problemáticos? Parte de la respuesta se relaciona con la influencia que tiene la conducta de otras personas en la vida 
personal del individuo. Las actitudes personales, los patrones de crianza y la forma de comunicación, afectan el desarrollo humano, por lo que no solo las buenas intenciones bastan. Las relaciones interpersonales van a ser el elemento fundamental del desarrollo del niño en particular y del ser humano en general.

Cuando los niños no cumplen con las expectativas de conducta esperada, decepcionan y ese sentimiento se transmite, se le hace saber, incluso sin querer. Estas decepciones se dan al no cumplir el niño con las ideas que los adultos tienen preconcebidas. Es necesario entonces, en primer lugar, revisar los sentimientos que se tienen sobre las expectativas de los padres, madres, maestros y otros adultos significativos, para comprender, en muchos casos, la conducta de los niños, de los adolescentes y de los adultos en general.

Así el niño forma su personalidad por medio de varios procesos, entre ellos:

- La identificación: sentimientos y deseos de parecerse a otras personas, lo que implica la interiorización de conductas y las actitudes de los padres, madres, maestros y otros adultos significativos.

- La imitación, repitiendo lo que hacen los demás.

- La observación, viendo qué hacen los otros.

Con estos procesos, se aprenden las actitudes, los valores y el enfrentamiento de los problemas, entre otros, y se aprende a hacer lo que social o familiarmente se espera. De este modo, se construye el núcleo de identidad personal, social y sexual. El poder responder a la pregunta ¿quién soy? se inicia por tanto, muchos años antes del período de la adolescencia, ya que las bases se ponen en los primeros años de vida.

Álvarez y Valladares (1987) plantean que la identidad y la personalidad del niño se desarrollan en un proceso de negociación de necesidades. A los niños y adolescentes no les podemos satisfacer todas las necesidades, pero tampoco se les debe complacer todos sus deseos. Los padres, madres, maestros y otras personas incluidos otros hijos en la familia también tienen necesidades y derechos que satisfacer y que se requiere priorizar, negociar y tomar decisiones.

La satisfacción y la insatisfacción son elementos que impulsan el desarrollo. Un equilibrio importante parte de la premisa de que madre/padre/hijo o, bien, los adultos/niños, 
tienen necesidades y que ambas partes deben satisfacerlas.

Esto mismo sucede con los docentes. Se convive e interactúa con los niños o los adolescentes de acuerdo con las normas y patrones de crianza que se han aprendido en la familia de origen, y las expectativas que se tienen como profesionales comprometidos con el crecimiento y desarrollo de los alumnos.

Esa motivación es la que mueve a la autora a tratar de ensayar, a partir de lo encontrado en el aula, una adaptación de un modelo de comunicación que permita un proceso reflexivo al docente para el logro de una convivencia armónica que favorezca el desarrollo humano integral y holístico de docentes y alumnos. Se retoman aspectos de la conducta de los docentes relacionados con la comunicación que fueron observados en el aula.

En el estudio realizado y tal como se mencionó, se observó la dinámica de dos quintos grados, de dos escuelas públicas, una ubicada en una zona urbana y otra en una zona urbano marginal. Los docentes encargados de estos grupos fueron una mujer y un hombre respectivamente. Las categorías y subcategorías que se conformaron en el análisis de los datos, se hicieron a partir de las notas recurrentes del proceso de observación no participativa, y en todo momento bajo la premisa del consenso. Los ejemplos que se seleccionan para ilustrar las categorías y subcategorías son tomados indistintamente de las observaciones hechas a la maestra y al maestro. Se utiliza el género de escritura masculino porque no es interés de la autora establecer una comparación entre ambos, sino más bien reflejar situaciones de aula en torno a la comunicación.

La comunicación no verbal, según plantean Cubero, Abarca y Nieto (1996), autoras del estudio, se refiere a las interacciones entre el maestro y el estudiante, por medio de lo gestual, sin excluir un grado mínimo de verbalización. El lenguaje corporal, entendido como los mensajes emitidos con diferentes partes del cuerpo, puede ir acompañado o no de breves expresiones verbales. Algunos ejemplos son:

- Una niña pregunta: "Maestro, ¿puedo pedir un corrector prestado?" El maestro contesta que sí, afirmando con la cabeza.

- Después de una señal que les hace el maestro, los alumnos se van caminando 
sin correr ni empujar.

- Una alumna pregunta: "Maestro ¿podemos guardar los útiles?" El maestro niega con la cabeza.

Este tipo de comunicación comprende todas aquellas acciones en que el maestro utiliza el cuerpo para comunicarse con los alumnos. Al respecto Jones y Canter (citados por Charles, 1989), hacen referencia a que el lenguaje corporal favorece la buena disciplina en el aula. Este lenguaje incluye la postura, el contacto ojo-ojo, las expresiones faciales, las señales, los gestos y la proximidad física. Por su parte Curwin y Mendler (1983), afirman que la comunicación no verbal es esencial en la disciplina de apoyo, porque estas técnicas permiten establecer contacto entre el maestro y el alumno, sin que se interrumpa al resto de los estudiantes. El poder de la comunicación no verbal es reafirmado por Wahlroos (1978) al manifestar que ésta es, en muchas ocasiones, más poderosa que la verbal.

La comunicación verbal que se encontró en las aulas incluye diversos tipos de interacción entre el maestro y los niños. Entre ellos se consideran en el presente trabajo los tipos de comunicación posesiva, breve, explicativa, cordial, contradictoria y los monólogos.

La comunicación de tipo posesiva se refiere a los mensajes del maestro, en que utiliza el pronombre "me" con el cual asume la responsabilidad de la conducta que es exclusiva del individuo o grupo con quien o quienes interactúa. Ejemplos de esto, se pueden observar en expresiones como:

- El maestro dice: "En primer lugar hay una tarea; voy a ver los cuadernos; me hacen el favor de sacarme el cuaderno."

- El maestro dice: "¿Bueno me dejan seguir hablando?" "Me traen una pajilla para el volcán y un mapa escolar de Costa Rica."

- El maestro dice: "Juan Carlos y Andrés, se me sientan por favor. Bueno, ahora sí, las personitas que van a hacer el refrigerio, se me juntan en un grupito; los demás en orden."

- El maestro dice: " A ver silencio; nadie me puede hablar en clase; lo he dicho más de mil veces". Responde a una pregunta de un niño y dice: "No me hablen, si no me han levantado la mano."

En la discusión de esta información encontramos que la comunicación posesiva es Volumen 4, Número 2, Año 2004 
aquella que utiliza constantemente el pronombre me, lo que según la literatura, no favorece que el alumno se responsabilice por sus acciones, sino que va a actuar, porque otra persona se lo pide. No está produciendo nada para sí mismo, sino para otra persona y esto evidentemente no favorece la construcción del conocimiento. En términos escolares, esto se traduce en una posición en la cual, el docente siente que tiene toda la responsabilidad de la situación de aprendizaje y el alumno es solo la persona depositaria de las situaciones que él determine. Este tipo de comunicación no permite, como señalan Curwin y Mendler (1983) que se establezca una concepción tridimensional de la disciplina, en donde el docente, los alumnos y las situaciones de aula, son las variables dinámicas que interaccionan. Por el contrario, este tipo de comunicación favorece y promueve una relación de verticalidad, en donde hay una autoridad única ejercida por el docente y una persona que obedece y es mandada que es el alumno. Desde una perspectiva psicológica, esto genera sentimientos de frustración para ambas partes. En el caso del docente, este no logra que se cumplan sus expectativas de tener alumnos autónomos y responsables; y para el alumno, que se siente incómodo de que lo traten como si fuera una persona incapaz y cuyos logros son y dependen de otras personas.

La utilización de mensajes breves, cuando se da una sola interacción verbal entre el receptor y el emisor del mensaje, es usada frecuentemente por los docentes. Algunas veces la respuesta del emisor a la reacción del receptor, puede ser no verbal. Ejemplos de este estilo de comunicación pueden ser:

- El maestro borra la pizarra. Dos alumnos dicen: "No maestro" y él mueve la cabeza afirmando su acción.

- El maestro pregunta: "¿Qué aprendieron de la autoestima?" Los alumnos hacen silencio; el maestro dice: "¿qué cualidad positiva aprendieron?" Un alumno levanta la mano y dice "alegre"; otro dice "feliz" y el docente continúa la clase.

- ¿Cuál es el valor de la prueba?", pregunta un alumno. "25 porque es un parcial", contesta el maestro.

- El maestro asigna un trabajo a los alumnos. "¿De tarea?" "pregunta un alumno". "No, aquí" contesta el maestro.

- El maestro borra la pizarra. Un alumno dice: "No maestro, no maestro". Otro alumno pregunta: "Maestro ¿qué hizo?" El maestro responde: "borrar"

- Los alumnos le dicen al maestro que las respuestas están correctas; el maestro 
les dice que no y ellos replican: "sí maestro". El maestro sonríe y les dice "no".

- "¿Ya terminó?" pregunta el maestro dirigiéndose a una niña. Esta le dice: "¿Puedo ir al baño?". El maestro contesta que sí afirmando con la cabeza "¿Ya van terminando para hacer la revisión?" pregunta el maestro, los niños asienten con la cabeza y él continua: "Esperemos que vengan Alberto y Bárbara que están en el baño".

- El maestro pregunta: "Ya, ¿usted levantó la mano?" La niña mueve la cabeza afirmativamente. Con la cabeza, el maestro la llama. La niña va al escritorio del docente, pregunta algo y regresa a su lugar; borra y sigue trabajando.

La comunicación que utiliza mensajes breves, se recomienda para trabajar instrucciones, disposiciones, advertencias, avisos, con los niños y los adolescentes, pues permite que no se distorsione el mensaje y se posibilita captar la esencia del mismo. En relación con el aula, este tipo de comunicación facilita que tanto el docente, como el o los alumnos, se comuniquen sin que se interrumpa el trabajo de los demás. Autores como Ginnot (citado por Charles: 1989), Wielkiewicz (1992), Becker (1989), hacen referencia a que el establecimiento y manejo de límites, tanto en el hogar como en la escuela, tienen que estar basado en reglas breves y claras.

Los diálogos extensos que se construyen entre el maestro y los alumnos, los cuales incluyen aclaraciones, razones y justificaciones sobre asuntos relacionados con el proceso educativo, se han denominado comunicación del tipo explicativo. Ejemplos de ellos son:

- El maestro explica: "Lean la página 36 del libro de Ciencias de tarea, para ver si terminamos esto del sistema solar. Traigan el cartoncito del sistema solar que compraron a principio de año". Un alumno dice: "Levanten la mano los que lo tienen" Otro niño pregunta ¿"Qué pasa con los que no lo tienen"? El maestro responde: "Lo fotocopian. ¿Qué pasa con los que no tienen la página 36 del libro?, pregunta otro niño, "Sacan el cuaderno y copian", responde el maestro. Todos gritan y pelean. El maestro aclara: "No vamos a copiar el resumen, sólo vamos a anotar lo que hay para mañana.

- El maestro pregunta: "¿Todos hicieron el examen de diagnóstico de matemáticas?". "Sí", responden a coro los niños. Una niña dice: "sólo Rodrigo no". El maestro pregunta a Rodrigo y éste dice "sociales no". El maestro le dice que le 
hace el examen después del recreo y le explica que esta prueba es de diagnóstico, para conocer qué recuerda de la materia estudiada el año anterior.

- Una alumna le pregunta al maestro: "¿Se pueden hacer los cuadros con la regla?". Este responde: "Tienen que hacerse con regla". Dos alumnos se levantan; comentan algo en voz alta y el maestro les dice: "A ver, a ver ¿qué pasó?" Víctor pregunta: "Maestro, ¿hay que hacer este dibujo grande?", "Sí, hay que hacerlo" porque se lo deben aprender."

- "Ya por favor" dice el maestro; "el que no trajo la tarjeta de vacunas será vacunado, así decía la circular. Mañana trabajamos por la tarde, porque les van a dar una charla sobre contaminación ambiental. Vamos a trabajar en donde era la sala de profesores" "¡Oh oh oh!", dicen los alumnos "¿Detrás de la soda"? pregunta una niña. "Sí" responde el maestro.

La comunicación explicativa permite al interlocutor, en este caso, a los alumnos, comprender las razones de las cosas que se les piden y comunican, lo que favorece los sentimientos de respeto, aceptación y fortalecimiento de la autoestima de los niños.

Es frecuente que la comunicación cordial se manifieste en el aula. Se incluyen en esta categoría aquellas interacciones verbales y no verbales del maestro y de los niños que construyen y favorecen un clima afectuoso y agradable en el aula. Ejemplos de esto, se aprecia en citas como las siguientes:

- Unos alumnos que habían salido traen un saco pesado. El maestro pregunta: "Ahora ¿qué hago yo con eso"? Un alumno dice: "Cuando viene mi papá por mí, le digo que lo lleve al gimnasio". "Muy bien, me parece bien", dice el maestro.

- El maestro se acerca al niño que preguntó sobre los dibujos y conversa con él sonriéndole. Otro niño pregunta: "¿Puedo ir al baño?". El maestro asiente. Otro niño se pone de pie y consulta con el maestro una página del libro de ciencias. Luego se sienta y le sonríe.

- Un niño dice: "Maestro, ¿ahora cantamos?" El maestro no dice nada; el niño insiste y dice: "¿Ahora cantamos?", el maestro le dice sí moviendo la cabeza, al hacerlo dejó de escribir en la pizarra y volvió la cara para donde los niños. Otro niño dice: "Verdad maestro que usted tiene la letra muy bonita", el maestro le dice "Sí" y se vuelve y sonríe a los niños que le hicieron el comentario. 
En la comunicación cordial, hay reflejo de un clima o ambiente de aula que permite el cumplimiento del trabajo escolar por parte de todos los actores. Wahlroos (1978), propone que una regla fundamental para que se dé una comunicación sana, es aquella en que es preciso emplear el tacto, la consideración y la cortesía, así como mostrar respeto por la otra persona y por sus sentimientos. También manifiesta que una misma situación puede ser vista, desde diferentes puntos de vista. Así la apertura al diálogo, por parte de los docentes y alumnos, es propicia para crear un ambiente adecuado en el aula.

Se puede observar en la situación del aula como los docentes utilizan frecuentemente los monólogos como parte de la comunicación con los niños. Estos son mensajes del maestro que no ofrecen oportunidad de reacción verbal al individuo o grupo a quien va dirigido. Algunos ejemplos son los siguientes:

- El maestro dice: "Levanten la mano los que no tienen hojas blancas". El maestro vuelve al frente del aula y dice: "Nadie se puede ponerse de pie, yo les doy las hojas". Procede a repartir hojas a todos, sin considerar los estudiantes que habían levantado la mano. "A ver", dice, "nadie puede hablar ni ponerse de pie; busquen un borrador de leche". Gritando les dice a los niños: "Nadie puede hablar, ni ponerse de pie" En forma más suave dice: "levanten la mano" y continúa repartiendo hojas a todos. El maestro vuelve a decir "nadie puede ponerse de pie". Sin embargo, nadie está de pie. "Silencio", dice el maestro, aunque nadie está hablando.

- El maestro dice: "les voy a enseñar cómo me enseñaron a mí a su edad; les quiero dar una explicación de lo que son las proporciones". Les da un ejemplo a los niños, y continúa diciendo: "Ahora ustedes pueden dibujar lo que gusten; la otra semana empezamos; necesito los materiales. También vamos a hacer lo siguiente, hay que dibujar árboles. Tal vez algún día podamos salir para usar nuestros sentidos." Los niños no comentan nada.

La comunicación por medio de monólogos refleja el desinterés por el interlocutor; impide el diálogo y, por lo tanto, el seguimiento de instrucciones que es muy importante para el logro de la tarea de enseñanza y aprendizaje. Wahlroos (1978) propone que cuando se necesita un proceso de comunicación, es preciso que se compruebe verbalmente que el mensaje está siendo entendido por el interlocutor. En caso contrario, podríamos estar 
haciendo suposiciones que provocan malos entendidos. Esto es particularmente válido para el medio escolar, pues es indispensable que el docente, en su calidad de adulto, verifique que sus instrucciones están siendo comprendidas.

Si analizamos esto en un largo plazo, se puede considerar que el ciclo lectivo en la escuela primaria permite que un docente esté aproximadamente entre 170 y 200 días anualmente con los alumnos, y estos pronto se acostumbran al estilo de comunicación. Si éste suele emplear monólogos, el alumno podría pronto dejar de prestar atención, porque sabe que su opinión o inquietud no son escuchadas. La buena comunicación escolar, si se piensa que el proceso educativo está centrado en el estudiante, debe estar basada en la capacidad de escucha del docente y en la habilidad para tener un radio de atención amplio que le permita tener control o supervisión sobre lo que sucede en el aula.

Los mensajes contradictorios en una misma comunicación, que el maestro dirige a un niño o a un grupo, también son frecuentemente observados. Ejemplos de estos son:

- Los niños están trabajando en grupo, el maestro les dice: "Planeen en voz baja; no tienen por qué estar hablando"

- Todos los niños están copiando pero algunos interrumpen porque se quedan atrás; el maestro dice: "No repito si están en otra cosa", pero inmediatamente repite

- El maestro grita: "A ver, silencio por favor. Pueden hacer lo que ustedes gusten". Habla con otros niños y de repente dice: "A ver, silencio; nadie me puede hablar en clase, lo he dicho más de mil veces".

La comunicación contradictoria, es, según Ginnot, (citado por Charles, 1989), un problema en todo momento, pero particularmente con los niños y adolescentes. Los dobles mensajes desconciertan al que está recibiendo la información pues no sabe a cuál de ellos atender. Generalmente estas situaciones provocan que el alumno reste credibilidad al docente $\mathrm{y}$, por tanto, los problemas de conducta tienden a incrementarse. Por su parte, Montcusí y Sala (s.f.) manifiestan que los niños necesitan puntos de referencia claros, y seriedad y respeto en su trato. Esto se consigue, afirman, si el maestro o los maestros de la escuela, son personas coherentes en sus propuestas y su conducta. 
En resumen, como hemos podido apreciar y según se desprende del estudio, la literatura señala que los estilos de comunicación breves, explicativos y cordiales son los que mejores resultados presentan en la interacción maestro-alumno. Los monólogos y la comunicación contradictoria, tienden a provocar reacciones de indisciplina en los alumnos producto del desconcierto y la confusión que generan. La comunicación de tipo posesiva responde a un esquema de comunicación que no favorece ni la responsabilidad ni el autocontrol en los niños. El uso adecuado del lenguaje corporal, es un recurso para el manejo efectivo de la disciplina.

Ginnot, (citado por Charles, 1989) señala que un ingrediente fundamental para el logro de la disciplina en el aula, es el uso de mensajes emocionalmente sanos y señala que estos son los que se refieren a la situación y no a la persona. Además, caracteriza estos mensajes como congruentes, armoniosos y referentes a las situaciones concretas que están viviendo los alumnos.

García, Rojas y Brenes (1994), señalan que el clima adecuado del aula, es aquel en que las personas son capaces de escucharse y decirse cosas positivas o felicitaciones. Muchas veces se encuentra presente en las escuelas, este ambiente del aula que favorece la comunicación. Tanto los alumnos como el docente, pueden establecer relaciones verbales que benefician el trabajo cotidiano. En otras ocasiones, como puede apreciarse en la información presentada, no se construye esta posibilidad. Dobson (1976, p. 107), señala que:

La disciplina educacional debería comenzar con la crucial interacción entre la maestra de la escuela primaria y sus alumnos. Por ser la primera voz oficial de la escuela, la maestra de primaria está en inmejorables condiciones para echar las bases de actitudes comportacionales positivas sobre las cuales, se puede edificar la futura educación o, por el contrario, puede llenar a sus alumnos de menosprecio y desdén.

Esta afirmación, válida aún hoy, señala que es entonces fundamental la forma en que el maestro se comunica con sus alumnos; esto es reafirmado por autores como García, Rojas y Brenes (1994), Charles (1989) y Stenhouse (1974) entre otros. 


\section{Comunicación y convivencia sana en el aula}

Sven Wahlroos (1978), hace una propuesta de 20 diferentes reglas de comunicación que permiten una convivencia sana en el medio familiar. En el presente apartado se pretende suministrar algunas herramientas que permitan al docente prevenir, apoyar y corregir la indisciplina en el aula provocada por dificultades en su comunicación para así fomentar el autocontrol y la autoestima de los estudiantes y para buscar la construcción de un clima de trabajo, donde se sienta satisfecho y tenga su salud mental protegida.

La perspectiva de Wahlroos (1978, pp. 20-21) y su conceptualización en torno a la importancia de la comunicación se desprende de la siguiente cita:

Por medio de la comunicación, en gran parte llegamos a ser lo que somos; a través de la comunicación aprendemos lo que sabemos; los problemas en las relaciones humanas se crean principalmente por causa de comunicación destructiva, y tales problemas se evitan o resuelven por medio de comunicación constructiva... Necesitaremos definir la comunicación como cualquier comportamiento que lleva consigo un mensaje que es percibido por otra persona. El comportamiento podrá ser o no verbal; será siempre una comunicación en tanto que lleve consigo un mensaje. El mensaje podrá ser o no intencionado, pero desde el momento en que es percibido, ha sido, de hecho, comunicado.

La primera regla que propone el autor para mantenerse mentalmente sano, es tener presente y "recordar que las obras dicen más que las palabras. La comunicación no verbal es más poderosa que la verbal" Wahlroos (1978, p. 25). En el trabajo de campo realizado en el estudio precitado, se encontró que muchas veces el mensaje de lo que se dice y lo que se hace, es contradictorio y esto genera muchos problemas. Cuando ambos procesos -la comunicación verbal y la no verbal- son incongruentes, el alumno se siente desorientado: ¿A qué le hace caso; a lo que le dicen o a lo que está viendo? Se considera que al ser la comunicación no verbal el primer medio de contacto del niño con el resto de los individuos, y también uno de los primeros medios de aprendizaje, por ejemplo cuando se imitan conductas o actitudes, ésta sigue teniendo mucho peso en la determinación de la conducta.

El adulto enseña muchas cosas por medio de lo que hace y hay una tendencia 
generalizada a reconocer esas acciones, como inadecuadas cuando los niños las reproducen, no reconociendo el peso que tienen las obras sobre las palabras. Es posible que el niño aprenda mejor lo que hacen sus maestros o reproduzca las conductas que ha visto en su hogar o en la televisión, en lugar de hacer lo que se le pide.

Ante esta situación, el maestro debe estar siempre atento a buscar el origen de las acciones del niño, antes de emitir un juicio de "mal comportamiento", muchas veces la causa es la forma en que él mismo se comunicó corporalmente y no necesariamente lo que dijo. Se debe revisar concientemente, cuál es el patrón de comunicación que se tiene y cómo este se expresa en lo oral y lo gestual. Quizá la máxima en este sentido -tal y como la propone Wahlroos (1978, p. 36)- es que los docentes, los padres y madres y cualquier adulto deben "expresar sus sentimientos positivos, tanto por medio de las obras como de las palabras, pero expresar sus sentimientos negativos únicamente por medio de palabras."

También el maestro debe estar atento a reconocer esos mensajes incongruentes en el proceso de comunicación del niño, informándole cuando se presentan y el efecto que está produciendo en los demás, al no poderse comprender lo que desea. Esto es muy importante para la formación del niño, como ser social y para ayudarle a clarificar su conocimiento de sí mismo.

La segunda regla que propone Wahlroos (1978, p. 37), se refiere a "definir lo que es importante y hacer hincapié en ello; definir lo que no tiene importancia y pasarlo por alto". En el estudio desarrollado por Cubero, Abarca y Nieto (1996) se encontró que el uso del tiempo por parte de los docentes no siempre es eficiente; gran cantidad de ese tiempo se pierde al llamar la atención sin precisar bien la conducta inadecuada o perturbadora que se quiere corregir, o bien dando importancia a conductas que podrían tener menos atención por parte del docente, en este segundo caso, muchas veces el alumno logra su objetivo de llamar la atención y sentirse miembro del grupo, mediante acciones perturbadoras que al ser atendidas prestándole atención, más bien se refuerza para que siga utilizando ese método.

En este sentido, el maestro debe conocer a sus alumnos y la etapa evolutiva en que se encuentran para poder discriminar y darle contenido a lo que es importante, tanto para el niño como para el grupo de alumnos. En muchas ocasiones, se encuentra que el adulto define lo que es importante para él y su trabajo, sin considerar, como se había mencionado, 
que en el aula debe existir una negociación entre las necesidades del docente para desarrollarse como persona y como profesional y, las del niño, para desarrollarse como persona y como estudiante.

Saber cuándo algo es importante y cuándo no, requiere estudio y preparación por parte del docente y una planificación preventiva de las consecuencias. Cuando las normas no se cumplen, el límite no se improvisa, sino se actúa congruente y consistentemente para facilitar en los niños la construcción del locus de control interno.

La máxima que recomienda el autor es: "Deje muy claro verbalmente así como por medio de su conducta, qué es lo que usted considera importante y qué cosas desea usted pasar por alto, porque acepta a su (alumno) como el ser humano que es" (p. 42). La autora del presente artículo, agrega por su parte, que el maestro debe procurar ser muy reflexivo en la determinación de este margen de acción para que luego pueda ser consistente con la decisión que tomó para crear así un ambiente de seguridad en los niños, pues estos pueden confiar en los límites que se han puesto.

Wahlroos (1978, p. 43), dice en relación con la tercera norma: "Sin dejar de ser realista, haga que su comunicación sea lo más positiva posible". Por comunicación positiva se está entendiendo, aquella que es respetuosa de la condición de ser humano que tiene el niño (y cualquier otra persona también), y cuya intencionalidad está dirigida a que se pueda construir una alternativa mejor, aunque sea, a partir del error o de la conducta inadecuada. Tan nefasto es reconocer únicamente lo que parece bueno en el niño, como reconocer únicamente lo que parece malo. El niño requiere aprender a tener confianza y seguridad $y$, esto solo se logra, cuando se es honesto para evaluar las normas de convivencia que el niño debe cumplir.

En muchas ocasiones, para que el maestro pueda ser realista y positivo a la vez, requiere pensar detenidamente lo que debe decir y cómo lo debe hacer. El no actuar, necesariamente, de inmediato sino dejar un espacio para la reflexión, es una enseñanza muy valiosa para el niño y una forma que el maestro puede utilizar, para ser justo y procurar preservar la autoestima de los alumnos. El maestro puede decir a un niño, por ejemplo: "Lo que hiciste es molesto para mí; luego quiero que nos sentemos a conversar al respecto". Con una intervención de este tipo, se está logrando que el maestro exprese sus 
sentimientos, a lo cual tiene todo el derecho, por su parte el niño se está enterando de que lo que hizo, está causando sentimientos de molestia en el maestro y que va a existir un momento para poder conversar o discutir esa situación. Se permite la reflexión de ambas personas. Esta misma actitud puede aplicarse en la relación del maestro con el grupo de estudiantes.

El sistema familiar, escolar y, en general, el social tienen una marcada tendencia a la corrección inmediata de la conducta inadecuada y esto está bien cuando lo podemos hacer positiva y respetuosamente; también se debe aprender a reconocer la conducta buena o el esfuerzo de mejoramiento que se está haciendo. El ser humano, dentro de sus necesidades básicas, requiere del reconocimiento ante sus acciones y, por tanto, sus éxitos así como sus esfuerzos de mejoramiento requieren ser alabados. Cuando a pesar del esfuerzo, el reconocimiento no llega, los niños elaboran una tendencia a tener un pobre concepto de sí mismos y, en el futuro, una probabilidad a actuar con una tendencia hacia la construcción de una identidad de tipo negativo, que lo hará infeliz y también al resto de las personas con las que se relacione.

La máxima de esta norma se puede resumir de la siguiente manera: "Aún la crítica necesaria puede hacerse de manera positiva y sin empequeñecer o humillar al niño. La crítica debería ser específica y debería ir acompañada de una demostración amistosa de la conducta que hubiera sido deseable" (Wahlroos, 1978, p. 48). Lo anterior es válido siempre, pero en especial, cuando se está trabajando con niños pequeños.

Las normas cuarta, quinta y sexta que propone el autor, se tratarán para efectos del presente ensayo como una sola. Wahlroos propone: "Sea claro y específico en su comunicación", (p. 50) "sea realista y razonable en sus afirmaciones" (p. 58) y "compruebe verbalmente todas sus suposiciones. Obtenga 'luz verde' de su interlocutor, antes de actuar" (p. 63).

Para una buena comunicación con niños en edad preescolar o escolar, así como con los adolescentes, se debe buscar un vocabulario adecuado y preciso para el nivel cognitivo. Las indicaciones vagas se prestan a interpretaciones basadas en procesos perceptuales personales $\mathrm{y}$, por tanto, pueden tener una alta probabilidad de ser transgredidas. Expresiones tales como "Ahora más tarde quiero que copien esto" o "Les dije que si podían 
comprar un mapa, lo hicieran, ¿por qué no lo trajeron?", provocan confusión en los alumnos, porque ¿cómo sabe un niño cuándo es "más tarde" o que era obligación comprar el mapa?

Una forma de buscar la claridad, propone Wahlroos, es proporcionado a las personas, en forma breve, una explicación de los motivos de las demandas, de las normas o de las decisiones y asegurándose que están entendiendo lo que se les está diciendo o pidiendo. Esto ayuda a que se desarrolle la capacidad para percibir la causa y el efecto de una situación. En muchas ocasiones, los maestros así como otros adultos que conviven con los niños, consideran, -no necesariamente en forma consciente-, que se pierde mucho tiempo explicando el por qué de las decisiones o bien el por qué de una determinada regla. Sin embargo, esto es una buena inversión de tiempo y esfuerzo, si nos situamos en el futuro, pues la comprensión de los motivos que están detrás de las decisiones normativas, genera una actitud de tolerancia hacia la normativa, aunque ésta no necesariamente se comparta, y elimina la posibilidad de que se perciban las reglas como imposiciones de carácter autoritario. Es necesario recordar que las reglas son para regular y facilitar la convivencia de las personas. Las imposiciones, -sean estas racionales o no- tienden a provocar reacciones impulsivas de rechazo. Esta actitud, a su vez, es causa de una gran gama de conductas inadecuadas en los niños (y también en los adultos), que fácilmente podrían evitarse, si se tiene claridad de lo que se pretende lograr con la norma.

Cuando se presenta una dificultad disciplinaria, porque la comunicación no es clara y específica es conveniente que el maestro (el padre, la madre, el encargado, el director de la escuela, el jefe o, simplemente, el adulto), aprendan a reconocer la parte de responsabilidad que han tenido en determinada situación. Wahlroos (1978) dice al respecto que es muy posible que se escuchen expresiones como: 'El no admite sus equivocaciones', pero es dudoso que se haya escuchado decir: 'Yo no admito mis equivocaciones', porque a la gente le gusta considerarse como muy razonable y se percibe como una debilidad admitir la posibilidad de equivocación y de reconocer las limitaciones que como seres humanos se tienen.

A la par de la tendencia de pensar que el estilo de comunicación personal es claro, se encuentra la suposición de que los demás están pensando de la misma manera y, por lo tanto, hay conjeturas que no se comprueban y que generan un efecto de "bola de nieve", provocando interpretaciones equivocadas. Así se antepone el criterio o el juicio personal, sin 
detenerse a valorar realmente cuál es el proceso de razonamiento y pensamiento que está llevando a cabo el interlocutor.

La suposición es parte del proceso de comunicación entre dos personas; es imposible no partir de este principio, pues sino sería tedioso explicar todos los detalles cada vez que se habla; pero se puede incorporar dentro del estilo de comunicación, la técnica de preguntas o afirmaciones para asegurarse de que lo están entendiendo e, igualmente, cuando se recibe un mensaje, se debe comprobar que se está entendiendo lo que el otro quiere comunicar. Esto reviste particular importancia, cuando se trabaja con niños y adolescentes que están justamente en un momento evolutivo caracterizado, entre otras cosas, por un enriquecimiento de vocabulario. Estas significaciones e interpretaciones sociales le permitirán ser parte activa de un complejo sistema que llamamos medio social.

La máxima de esta cuarta, quinta y sexta reglas estriba en considerar que los interlocutores "comparten la responsabilidad de dejar bien claros los deseos y preferencias, lo mismo que las decisiones" (Wahlroos, 1978, p. 71)

La regla séptima indica la necesidad de que se "reconozca que cada suceso puede ser considerado desde diferentes puntos de vista" (Wahlroos, 1976, p, 72). Cuando el maestro tiene una actitud de respeto hacia el proceso evolutivo de la otra persona, entonces puede considerar "el no estar de acuerdo" como una oportunidad de intercambiar opiniones interesantes. Cada individuo ha elaborado su propia percepción de las cosas, debido a la forma en que va construyendo su historia; no hay dos historias de vida igual, ni siquiera la de los gemelos idénticos. Por eso no puede existir un solo modo de ver las cosas; cada uno manifiesta su individualidad en la manera cómo se organiza la información que el medio le suministra. Si se considera lo anterior, ¿no sería justo para las otras personas que se estime de antemano que pueden pensar diferente, entonces se debe tratar de comprender cómo ven las cosas para que así la comunicación se pueda dar fluidamente?. Quizá esto sea muy importante para ayudarle al niño a comprender cómo la sociedad ha elaborado su propio código de convivencia y se le pueda facilitar oportunidades para el desarrollo de comportamientos pro-sociales, entendiendo como tales, según lo propone Papalia y otros (2001, p. 431) "la capacidad de ayudar a los demás sin esperar retribución. 
Cuando el docente o los padres no permiten que el niño exprese su propia comprensión del mundo o de la situación que está viviendo, éste no solo vive sentimientos de frustración, sino no logra desarrollar ideas y opiniones independientes y creativas, puede elaborar conductas de dependencia del criterio del adulto $y$, tal vez lo más grave, es que no se le permite aprender a discrepar de otro, reconocer mejores opiniones o defender las propias por medio de la discusión sana.

La discusión de puntos de vista diferentes no es inadecuada por sí misma, lo que sucede es que generalmente no se tolera la discrepancia y se irrespeta. Para poder expresar un punto de vista diferente, se requiere que la otra persona tenga una actitud de escucha y respeto. Al negársele a un niño la posibilidad de expresar su punto de vista de las cosas, se le están comunicando sentimientos de desprecio y manifestándole tácitamente que sus opiniones no valen nada, con lo que se limita su capacidad de expresión y de elaboración de nuevas ideas.

En el caso de que no se aprecie el valor de las opiniones del niño, estos generalmente revelan su frustración de alguna manera. Los adultos suelen considerar ese tipo de manifestación como "malacrianza" o "indisciplina". Cuando el niño verbaliza que el adulto ha sido injusto o bien lo expone actuando inadecuadamente, es recomendable decirle expresiones tales como: 'muéstrame de qué modo he sido injusto'. De esta manera, se abre un espacio para que el niño manifieste sus sentimientos de enojo, en una forma respetuosa y se puede conocer cuál es su punto de vista de la situación y, a partir de ahí, se pueden negociar las percepciones del adulto y las del niño.

Según Wahlroos (1978, p. 78 ), la máxima de esta regla es: "siempre que alguien contempla una situación de manera diferente, es digno de ser escuchado"

En la octava norma se propone: "reconozca que los miembros de su familia son peritos en usted y su comportamiento", (Wahlroos, 1978, p, 79). Para los efectos de la relación maestro-alumno, se propone una lectura como la siguiente: 'los niños pronto aprenden a reconocer cuál es el estilo de comportamiento del docente y a actuar, en consecuencia'. Rápidamente los alumnos establecen los estilos de comportamiento propios para responder a esa realidad, sea aceptándola o rebelándose a ella. El docente ha aprendido formas de relacionarse con los demás, sean estos comportamientos autoritarios 
fundamentados en el valor de la obediencia por sí misma, y donde se ejerce el poder necesario para someter al niño, o bien, en estilos sobreprotectores o permisivos que se asientan en una forma de control donde no se dirige, no se guía, ni se exige al niño, antes bien se apela a que el niño tiene la capacidad para tomar decisiones, la mayoría de las veces sin asumir las consecuencias, o bien, un docente con un estilo competente que puede aplicar un control firme y afectivo, con un alto valor de la obediencia pero estimulando la independencia, capaz de dirigir una propuesta de normas congruentes para la buena convivencia en el aula,

En un ambiente de aula, la percepción de los niños -y de otras personas- refleja en mucho lo que el docente es, ya que puede manifestar conductas y sentimientos de los cuales no se ha percatado, pero que las demás personas sí lo hacen. Es necesario, por tanto, escuchar atentamente lo que los estudiantes dicen o se deben analizar con cuidado las reacciones de los alumnos; a través de ellas el docente se puede dar cuenta de cuáles son generadas, a partir de su propio comportamiento. La máxima de esta norma se puede presentar de la siguiente manera: "... jamás hay que negar la validez de lo que otra persona, sobre todo... (alguien cercano).., dice acerca de la impresión que uno da o de "cómo cae". En vez de eso, hay que preguntar cuál ha sido la impresión que uno ha dado, para poder uno darse cuenta de lo que comunica inconscientemente". (Wahlroos, 1978, p. 84). Lo anterior le permite al maestro aumentar el conocimiento que tiene sobre sí mismo y la oportunidad de trabajar consigo mismo, de manera que su comunicación sea congruente y consistente. Esto de acuerdo con lo observado en el estudio reseñado, facilitará el manejo de los límites con los alumnos y la prevención de la indisciplina en el aula.

La novena regla que plantea Wahlroos, se refiere a "no permitir que las discusiones se transformen en altercados destructivos" (p. 85), en particular esta norma tiene una doble importancia para el docente. Por un lado, desde la perspectiva personal, el maestro debe conocer las limitaciones de su tolerancia para así poder elaborar una serie de recursos que le permitan no perder el control. En observaciones realizadas en el aula, se pudo comprobar como, en algunas ocasiones, el docente "pelea" con el alumno, lo que de ninguna manera es conveniente. Cada docente debe conocer cuáles son las situaciones que lo enojan y le hacen perder el control y, de antemano, debe estar preparado para prevenir esa conducta y poder dar una respuesta al alumno que le permita aprender de la conducta de su maestro. 
En segundo lugar y, también basado en la experiencia señalada, se encontró que no se dio la intervención del docente ante las situaciones de discusión o altercados violentos entre los alumnos, lo que ocasionó que éstos se lastimaran o que el conflicto se hiciera más grande. El maestro debe estar siempre atento al comportamiento de sus alumnos dentro del aula y fuera de ésta y debe intervenir cuidando el bienestar de los niños y la salvaguardia de un ambiente propicio para la convivencia armónica, procurando "no permitir que las discusiones se transformen en altercados destructivos" que los niños tengan un espacio neutral en el cual manifestar su desacuerdo para llegar a una solución pacífica del mismo. Por ningún motivo un docente debe dejar que una situación genere violencia, ni debe ignorar su papel formador y conciliador.

Se debe recordar que un altercado es una comunicación, pero que en este caso, la misma tiene el propósito, parcial o total, consciente o inconsciente, de lastimar al compañero, señala Wahlroos (1978, p. 85). Siempre que una comunicación se está convirtiendo en un altercado se presentan algunos signos externos, tales como el aumento del volumen de la voz, uso de palabras negativas, tono hostil, etc. Estos signos son los que deben atenderse de inmediato y se debe recordar que todos los seres humanos son propensos a tener sentimientos inadecuados para la convivencia social; sin embargo, esto nunca justifica que se pueda dañar la autoestima de los demás.

La máxima a esta norma se podría proponer de la siguiente manera: "Hay que enseñar a los niños a respetar el derecho que tienen los demás de expresar su opinión y debería mostrárseles... cómo pueden manifestarse respetuosamente los desacuerdos" (Wahlroos, 1978, p. 93).

Como regla décima Wahlroos (p. 94) propone: "manifieste sus sentimientos abiertamente y con sinceridad. Traiga a colación todos los problemas de importancia, aún cuando tema que el hacerlo incomode a su compañero. No camine sobre brasas". Desde el punto de vista de la comunicación entre un adulto y un niño, este punto exige un cuidadoso análisis. Dice el autor que dejar un problema de importancia sin discutir, es como no aplicar un tratamiento médico a una infección ulcerosa. El problema no va a desaparecer, pues al igual que una infección progresiva se pondrá cada vez peor. 
Los niños tienen el derecho a ser formados integralmente y esto incluye el derecho de conocer la forma correcta de expresar todo tipo de sentimiento para manifestarlo de manera respetuosa y aprender a respetar los sentimientos de los demás. Caminar sobre las brasas, significa dejar de tratar las dificultades y acumular sentimientos inadecuados hacia el otro, ya que provoca resentimiento, desconfianza y desprecio.

Los docentes pueden adoptar un modelo para que los niños, -mujeres y hombreslogren expresar sentimientos y tener recursos para evitar la intensificación de los mismos, si no están bien encausados; esto tarde o temprano causará conflictos en las relaciones humanas. Esta es una de las causas más comunes de la transgresión de normas de convivencia entre los niños.

El docente también tiene el derecho, como propone Canter (citado por Charles, 1989), a expresar sus sentimientos y demandar de los niños el respeto y consideración a su trabajo y a su salud mental, por lo que puede planificar un clima de aula, en donde la comunicación abierta de los sentimientos y el respeto a los mismos sean válidos.

Como máxima o corolario el autor propone: "la regla 10 jamás debe utilizarse para comunicar de modo destructivo sentimientos. No existe integridad alguna en elegir de un modo destructivo más que uno constructivo aquello que uno siente" (Wahlroos, 1978, p. 105)

En referencia a la regla de comunicación onceava, se señala: "No utilice técnicas desleales de comunicación; no emprenda una 'pelea sucia'". (Wahlroos, 1978, p. 106) Generalmente las técnicas desleales aparecen como recursos para poder manejar el enojo y la ira. El docente -como ser humano- no está exento de esos sentimientos y también debe aprender a manejarlos para así conformar un modelo sano por imitar.

Wahlroos en su libro, analiza una serie de técnicas desleales de comunicación. La autora se va a referir a aquellas, que en el estudio se pudieron observar en el uso frecuente de los docentes. Entre ellas están fingir que la otra persona ha hecho una afirmación o demanda irrazonable; pretender adivinar el pensamiento de la otra persona, manifestando conocer la motivación que tiene para decir las cosas; cambiar de tema, generalmente utilizando contraataques; formular varias acusaciones a un mismo tiempo; emplear la lógica para esconderse de la realidad emocional; interrumpir al que está hablando con frases como 
"¡Pero eso no es cierto!, yo no he...!"; intimidar; culpar al otro por algo que no puede remediar o, bien, negarse a perdonar; utilizar la humillación, insultar, echar en cara; utilizar el sarcasmo y el ridículo, entre otros.

Si bien en el análisis de la información realizado en el estudio de referencia, se trató de reflejar lo más fielmente posible la realidad de aula encontrada, muchas técnicas quedaron registradas en otras categorías y subcategorías; por ejemplo, el sarcasmo, los laconismos, las amenazas, los regaños, las órdenes, los comentarios devaluativos, etc., que se registran como el estilo que tiene el docente de llamar la atención, o bien el uso de la voz, la privación de derechos y otros.

Para efectos del presente artículo, se señalan las técnicas anteriores porque ofrecen el denominador común de que afectan la autoestima del receptor del mensaje; pero también del emisor del mismo. Estos recursos de la comunicación, como se señaló, encierran un enmascaramiento de sentimientos de ira y frustración que se proyectan al trato con las otras personas. Cuando hay dificultad para manejar determinadas situaciones como por ejemplo la conducta de los niños en el aula, aparecen sentimientos de impotencia y reacciones de agresividad y violencia que desvalorizan a la otra persona; pero también al que está utilizando el estilo desleal.

Wahlroos trata estas técnicas desleales ampliamente, porque en ellas se reflejan las dificultades en la construcción de la personalidad y en la socialización que tiene una persona, al necesitar plantear su interrelación con los demás a partir de recursos destructivos para defenderse de un medio, en el cual se siente amenazado.

Como se ha señalado en otros momentos la necesidad de autoconocimiento y de autocontrol son indispensables para el docente en todos los niveles; pero es particularmente importante cuando se está trabajando con niños pequeños, tal y como lo propone Walhroos (1978, p. 113)

La doceava regla de comunicación de Wahlroos (1978, p. 170), dice: "guíese por el efecto y no por la intención de la comunicación propia", es recogido por la sabiduría popular en un viejo proverbio que dice: 'de buenas intenciones está empedrado el camino al infierno'. Esto quiere decir que no basta con solo tener buenas intenciones en la 
comunicación; es necesario también prestar atención al efecto que ella causa sobre el otro. Los docentes -y otros adultos-, con frecuencia asumen que su comunicación con los niños es clara y concisa y, parten de esta premisa, sin considerar que la otra persona puede estar entendiendo y comprendiendo cosas diferentes. Estar atento a la reacción de los niños es la máxima de esa regla, así como examinar "qué es lo que hay en el propio comportamiento que hace que la otra persona se forme una impresión distinta de aquella que usted en forma consciente trata de comunicar" (Wahlroos, 1978, p. 173).

La treceava regla es muy importante para la formación y el desarrollo pleno de los niños y adolescentes; se refiere a que "acepte todo sentimiento ajeno y procure comprenderlo; no acepte todos los actos, pero procure entenderlos". Líneas arriba se mencionó la importancia de expresar los sentimientos. En esta norma, se hace hincapié en el respeto y la consideración que se debe tener a los sentimientos ajenos. El aula es un lugar de convivencia y en ella puede caber toda manifestación sentimental, siempre y cuando esta no dañe la autoestima ni el autoconcepto de ninguno de los miembros del grupo. Se solicita que exista una comprensión de esos sentimientos y no necesariamente se deben aceptar los actos que se deriven de los mismos; esto es lo que marca la diferencia: una persona puede comprender y respetar un sentimiento, pero no estar de acuerdo con la expresión que la otra persona haga, no obstante, también debe procurar entenderlos.

Se debe recordar que cuanto más pequeños sean los niños, menos recursos verbales y lingüísticos tienen para comunicarse; en muchas ocasiones, cuando actúan están comunicando sus sensaciones y emociones, por lo que el entendimiento de los mismos es requisito para facilitarles la expresión de sus inquietudes. Esto último no quiere decir que se deba tolerar todo comportamiento. Por el contrario, el niño debe conocer y practicar las normas sociales; además, necesita aprender la mejor forma de expresarse.

La máxima de esta norma podría resumirse en decir que todas las personas tienen derecho a sentir y la expresión de ese sentimiento está regulada por el código social de la comunidad en donde se viva. Todos tienen derecho a recibir comprensión de los sentimientos, más no aceptación indiscriminada de sus actos.

La norma catorce, señala que: "es preciso emplear el tacto, la consideración y la cortesía, así como mostrar respeto por el compañero y por sus sentimientos" 
(Wahlroos, 1978, p. 180). La cortesía y el buen tacto (entendido este como el acercamiento a otra persona con respeto, sinceridad y una actitud abierta al diálogo) son esenciales para poder crear un ambiente de aula propicio para el aprendizaje. En el caso de la investigación reseñada se encontró que cuando el maestro se comunica en forma cordial con sus alumnos, incluso cuando tiene que llamarles la atención, el clima del aula es afable y ameno para las relaciones interpersonales y para el cumplimiento de las tareas escolares, tanto del maestro como de los alumnos.

Un maestro siempre encontrará circunstancias en el aula con las cuales puede enseñarles a los alumnos a tener tacto en el manejo de situaciones que lo requieren. Hablar con un tono de voz bajo con el niño que tiene problemas, hacerlo a solas y con mucho respeto, le está enseñando al niño a no sentirse humillado por las circunstancias, pero que se requiere un cambio para mejorar las relaciones interpersonales. Al mismo tiempo, el docente adquiere autoridad moral para solicitar comportamientos similares al niño y al grupo en general.

La autora propone colocar juntas las reglas quince, dieciséis y diecisiete, por cuanto tienen como objetivo común, la búsqueda de una comunicación breve y respetuosa que, como se demostró en las citas etnográficas reseñadas, son muy adecuadas para el buen manejo de la disciplina en el aula. Wahlroos (1978) las señala de la siguiente manera: "No acostumbre sermonear ni dar prédicas, más vale preguntar" (p. 186), "No emplee las excusas ni se deje engañar por ellas" (p. 191) y "no acostumbre regañar, gritar ni Iloriquear" (p. 211). En todos estos enunciados, la recomendación a la comunicación de tipo asertivo se encuentra implícita, y se caracteriza justamente porque propone expresar los asuntos, sin tener que recurrir a una serie de conductas perjudiciales que se presentan como dañinas para la comunicación fluida.

Los padres, madres y maestros recurren al sermón con la sana intención de tratar de que el niño comprenda que debe cambiar su conducta. Se le suele llamar sermón porque quien utiliza esta técnica se comunica, generalmente, en forma de monólogo sobre el tema del cual quiere llamar la atención. Como la conducta perturbadora de los niños gira generalmente sobre las mismas cosas, el sermón se vuelve repetitivo y deja de ser atendido por el interlocutor que asume que ya ha oído eso y no le presta mayor atención, o sea el objetivo que se busca se desatiende por completo. 
Esta técnica no siempre se percibe como inadecuada o desleal; en algunas ocasiones con los niños pequeños funciona si es breve, concreta, y cuando hay una necesidad imperiosa de informar al niño de algo o bien cuando se está tratando de crear rutinas y hábitos. Es condición que se tenga claro, de que de verdad el niño necesita esa información o cuando es el niño el que pide esa información. Por ejemplo, la información sobre la necesidad de lavarse los dientes después de las comidas, pasa a ser un sermón cuando repetidamente se le dice a los niños: "Hay que lavarse los dientes después de cada comida, porque si no lo hacemos, los dientes..., etc.", se dan muchas razones, a veces incompresibles y carentes de significado para el niño. En este caso la repetición aburre e indispone al niño, ellos mismos suelen repetir el sermón, casi con las mismas palabras, pero con ademanes o tono de voz devaluativo. Es mejor evitar este tipo de acciones para ayudar a que el niño incorpore realmente la norma y no que esta se convierta en algo tedioso y, por lo tanto, sujeto a ser confrontado mediante una conducta perturbadora. La recomendación o máxima, en este caso, es utilizar las preguntas, para confirmar si el niño ha entendido y también para poder profundizar en la situación recurriendo al diálogo que siempre es un mejor recurso para la sólida construcción del conocimiento.

Las excusas se utilizan para ocultar una situación que está causando alguna dificultad; por ejemplo, si se les dice a los niños: "llegué tarde porque se le acabó la gasolina al carro", esto es una excusa en la cual no se dice toda la verdad, o sea, el hecho de que al carro se le acabe la gasolina, se debe al descuido porque no se le prestó atención al medidor correspondiente. Es necesario enseñar al niño la diferencia entre excusas y razones; la excusa busca ocultar los motivos reales, las razones son explicaciones de esa realidad. Ayudar al niño a encontrar la diferencia, es un modo de enseñarle a ser honesto y sincero y a aceptar las consecuencias de las acciones, con lo que se logrará que pueda ejercer el autocontrol sobre las decisiones que toma.

El maestro puede recordar que "siempre es posible salir al encuentro de una excusa con una afirmación razonable que señale la realidad y manifieste comprensión por los sentimientos de la otra persona", según lo señala Wahlroos (1978, p. 210). Esto es importante en la formación del niño y al adulto le da la oportunidad de ser asertivo con aquel que siempre tiene una excusa para explicar las acciones, pero no son necesariamente razones válidas para la misma. 
En relación con la costumbre de regañar, es conveniente recordar que el regaño es aquel tipo de comunicación verbal que se acompaña de una serie de signos no verbales, que permiten a la otra persona reconocer que hay enojo. Estos signos se refieren al tono y timbre de la voz y a las manifestaciones propias de la impaciencia, como por ejemplo colocarse las manos a la cintura, señalar con el dedo índice, arrugar la cara y abrir los ojos a su máxima expresión, hay otras manifestaciones fisiológicas no visibles tales como aumento del latido cardíaco y de la presión sanguínea, entre otros. Generalmente cuando se le pregunta a alguien, si está regañando a otro, dice que no, que lo que hace es recordarle a la otra persona cómo es que debe comportarse; sin embargo, ese recordatorio busca comunicar una enseñanza, por el contrario Wahlroos (1978, p. 212), señala que el regaño no lleva implícito el aprendizaje, sino que es una interacción de tipo neurótico que provoca una reacción en la otra persona de no atender la conducta solicitada.

El llanto del maestro ante las conductas perturbadoras tiene un efecto impactante en el niño y en el adolescente, (también en los adultos), que pierde la seguridad y el sentimiento de resguardo que lo debe cobijar al estar en la escuela. El llanto implica debilidad y lasitud, también frustración y minusvalía y el mensaje que se e da a los alumnos es: "Yo no puedo con ustedes; estoy desprotegida o desprotegido". De ahí la importancia de utilizar las técnicas de la disciplina preventiva, con las cuales se puede actuar de tal modo que se pueden aplicar las normas, casi en forma automática y se eliminan muchas de las situaciones de indisciplina complicadas que se presentan en el aula.

El maestro que sabe planear el tiempo, las actividades y el uso del espacio tiene mayores posibilidades de manejar adecuadamente las diferentes conductas de los niños, sin llegar a manifestar esa sensación de impotencia frente a las múltiples reacciones que pueden revelar los niños en un momento dado. Las normas claras y una aplicación consistente de parte del maestro, eliminan el regaño y el llanto, y las situaciones de tensión disminuyen, porque si se siguen las normas, no hay necesidad de regañar, y si se transgrede, entonces ya se ha previsto por adelantado, cuál es la consecuencia.

La máxima de esta serie de reglas, es "acercarse al niño y decirle con amabilidad en voz baja la petición al oído. El acto en sí expresa un sentimiento de intimidad y, por lo general, hace que el niño se sienta bien" (Wahlroos, 1978, p. 225). 
La regla dieciocho, dice "Aprenda cuándo usar el buen humor y cuándo tomar las cosas en serio". El humor, dice Wahlroos (1978, p. 226), es uno de los atributos más maravillosos que un ser humano puede tener. Algunas de las tendencias actuales de enfocar las posibilidades del ser humano para ser feliz, incluyen el uso del humor, como uno de los factores protectores más fuertes. El humor utilizado adecuadamente en una clase, puede lograr que momentos de tensión o cansancio sean sobrellevados con mayor facilidad. Pero el humor no tiene solo el significado anterior, también el ser humano puede desarrollar la capacidad de reírse de sí mismo y de ver el lado humorístico de las situaciones y gozar con ello. Se pueden solventar mejor muchas equivocaciones y debilidades, si uno las asume con buen sentido del humor.

Si el humor es fiable, respetuoso y oportuno, puede ayudar a evitar discusiones destructivas. La recomendación que debe guiar el uso del humor se puede resumir así: "cuando bromear es divertido es porque los dos compañeros comprenden que no existe intento alguno, consciente o inconsciente de herir la propia imagen de la otra persona", según lo indica Wahlroos (1978, p. 228). El maestro, según se despende de lo anterior, no debe abusar de este recurso, ni permitir su uso si a los niños les resulta incómodo.

La regla diecinueve que plantea Wahlroos (1978, p. 234), señala lo que muchos otros autores llaman una regla de oro: "aprender a escuchar". El autor va más allá de asegurar que es prácticamente imposible educar a los niños, si no se aprende a escucharlos. El escuchar activamente a los niños, implica una manifestación de verdadero interés por sus sentimientos y opiniones, así como un evidente interés para tratar de entenderlo.

Muchas personas utilizan en su comunicación una actitud de 'preparación para la respuesta' en lugar de escuchar lo que se les está diciendo. Otros que parecen no escuchar ni oír, contestan como si la conversación fuera un monólogo, solo que ellos consideran que tienen la verdad y la razón.

Los niños pequeños al igual que todas las personas tienen derecho a ser escuchados y que sus opiniones sean consideradas, aunque no parezcan, en un primer momento que son interesantes. Si se le ahonda al niño en su razonamiento, el maestro puede estar descubriendo un mundo muy singular y diferente del suyo. También es necesario enseñarle al niño a escuchar $y$, una forma simple, que propone el autor, es pedirle que repita la 
información que se le acaba de dar.

Tanto para poder escuchar, como para escuchar, se necesita que la comunicación sea en el momento oportuno. Para que la comunicación sea sana, positiva y asertiva debe darse en condiciones óptimas, y, esto es algo que también puede enseñarse. La máxima de esta regla implica que la escucha siempre debe tener un carácter positivo; debe ir dirigida a la construcción de un diálogo que permita el desarrollo personal de los interlocutores.

La regla veinte que propone el autor, es una advertencia importante, dice: "Cuidado con emplear juegos destructivos", se encuentra relacionada con el hecho de que hay juegos en las transacciones que se realizan en las relaciones interpersonales y, que estos juegos, no deben producir un daño en la autoestima de las personas. Es muy fácil reconocer lo que los demás hacen inadecuadamente; pero es muy difícil reconocer las propias faltas y debilidades. El maestro debe ser muy cuidadoso cuando se va a comunicar con el niño. En este sentido, no debe permitir que el niño recurra a las técnicas desleales y también debe visualizar el resultado de la comunicación que realiza con los padres y madres, sobre el comportamiento de los niños.

\section{Autoanálisis del estilo de comunicación:}

A continuación se presenta un cuadro con algunas conductas relacionadas con las reglas de comunicación propuestas por Walhroos, de manera que cada persona pueda autoanalizar cómo las está utilizando. El periodo de tiempo que quiera utilizar como referencia es libre, puede ser una semana, un mes, un día, una quincena, pero si es necesario pensar en la frecuencia con que recurre a una forma particular de comunicarse.

Este cuadro no es un test, ni mucho menos. Se trata de brindar una lista de verificación que permita al lector identificar cómo cumple con estas reglas y concretar acciones que le permitan el mejoramiento de su accionar cotidiano. 
Reglas de Comunicación

Detalles para la autorreflexión

\begin{tabular}{|c|c|c|c|}
\hline Regla de comunicación & $\begin{array}{l}\text { Lo } \\
\text { hago }\end{array}$ & $\begin{array}{l}\text { No lo } \\
\text { hago }\end{array}$ & $\begin{array}{c}\text { A } \\
\text { veces } \\
r\end{array}$ \\
\hline \multicolumn{4}{|l|}{$\begin{array}{l}\text { Regla 1: recordar que las obras dicen más que las palabras. La } \\
\text { comunicación no verbal es más poderosa que la verbal. }\end{array}$} \\
\hline \multicolumn{4}{|l|}{$\begin{array}{l}\text { Expreso sentimientos positivos, tanto por medio de las obras como } \\
\text { de las palabras }\end{array}$} \\
\hline$>$ expreso sentimientos negativos únicamente por medio de palabras. & & & \\
\hline \multicolumn{4}{|l|}{$\begin{array}{l}\text { Regla 2: definir lo que es importante y hacer hincapié en ello; } \\
\text { definir lo que no tiene importancia y pasarlo por alto. }\end{array}$} \\
\hline \multicolumn{4}{|l|}{$\begin{array}{l}\text { Dejo muy claro verbalmente así como por medio de mi conducta, } \\
\text { qué es lo que considero importante. }\end{array}$} \\
\hline \multicolumn{4}{|l|}{$\begin{array}{l}\text { Tengo claro qué cosas puedo dejar pasar por alto, porque acepto al } \\
\text { alumno como el ser humano que es. }\end{array}$} \\
\hline \multicolumn{4}{|l|}{$\begin{array}{l}\text { Regla 3: Sin dejar de ser realista, haga que su comunicación sea } \\
\text { lo más positiva posible. }\end{array}$} \\
\hline$>$ Hago crítica solamente cuando es necesaria. & & & \\
\hline \multicolumn{4}{|l|}{$\begin{array}{l}\text { Hago crítica de una manera positiva y sin empequeñecer o humillar } \\
\text { al niño. }\end{array}$} \\
\hline \multicolumn{4}{|l|}{$\begin{array}{l}\text { Hago crítica de manera específica y acompañada de una } \\
\text { demostración amistosa de la conducta que hubiera sido deseable. }\end{array}$} \\
\hline \multicolumn{4}{|l|}{ Regla 4: Sea claro y específico en su comunicación } \\
\hline \multicolumn{4}{|l|}{$\begin{array}{l}\text { Considero las condiciones evolutivas de los estudiantes para } \\
\text { comunicarme con ellos. }\end{array}$} \\
\hline \multicolumn{4}{|l|}{$>$ Tengo claridad de lo que deseo solicitar a los estudiantes } \\
\hline \multicolumn{4}{|l|}{ Concentro mi esfuerzo en comunicar lo que deseo a los estudiantes } \\
\hline \multicolumn{4}{|l|}{ Regla 5: Sea realista y razonable en sus afirmaciones. } \\
\hline \multicolumn{4}{|l|}{$>$ Analizo lo que voy a solicitar a los estudiantes } \\
\hline \multicolumn{4}{|l|}{$>$ Soy razonable en lo que solicito a los estudiantes } \\
\hline \multicolumn{4}{|l|}{$\begin{array}{l}\text { Regla 6: compruebe verbalmente todas sus suposiciones. } \\
\text { Obtenga 'luz verde' de su interlocutor, antes de actuar. }\end{array}$} \\
\hline \multicolumn{4}{|l|}{$\begin{array}{l}\text { Compruebo las suposiciones que me } \\
\text { intercomunicación con los estudiantes. }\end{array}$} \\
\hline \multicolumn{4}{|l|}{$\begin{array}{l}\text { Permito que los interlocutores compartan la responsabilidad de } \\
\text { dejar bien claros los deseos y preferencias, lo mismo que las } \\
\text { decisiones. }\end{array}$} \\
\hline \multicolumn{4}{|l|}{$\begin{array}{l}\text { Regla 7: reconozca que cada suceso puede ser considerado desde } \\
\text { diferentes puntos de vista }\end{array}$} \\
\hline \multicolumn{4}{|l|}{$\begin{array}{l}\text { Respeto los puntos de vista de las demás personas, aunque no los } \\
\text { comparta. }\end{array}$} \\
\hline \multirow{2}{*}{\multicolumn{4}{|c|}{$\begin{array}{l}\text { Escucho atentamente los puntos de vista de las otras personas. } \\
\text { Regla 8: reconozca que los participantes en su aula son peritos en } \\
\text { usted y su comportamiento. }\end{array}$}} \\
\hline & & & \\
\hline \multicolumn{4}{|l|}{ Acepto las opiniones que los estudiantes tienen sobre mí. } \\
\hline \multicolumn{4}{|l|}{$\begin{array}{l}\text { Admito que en mi comunicación puedo estar utilizando mensajes } \\
\text { inconscientes. }\end{array}$} \\
\hline$>$ Escucho las opiniones que los estudiantes tienen de & & & \\
\hline
\end{tabular}




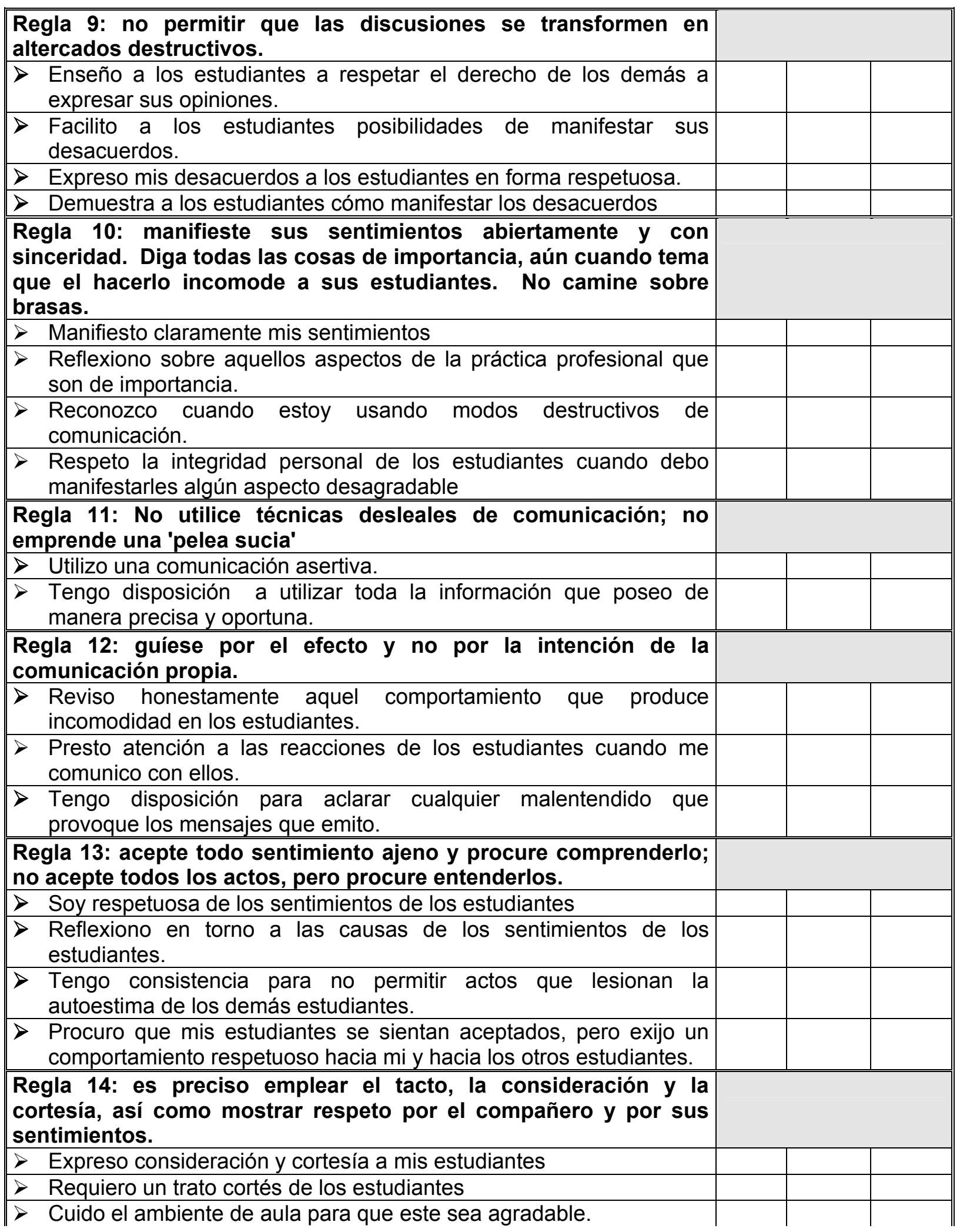




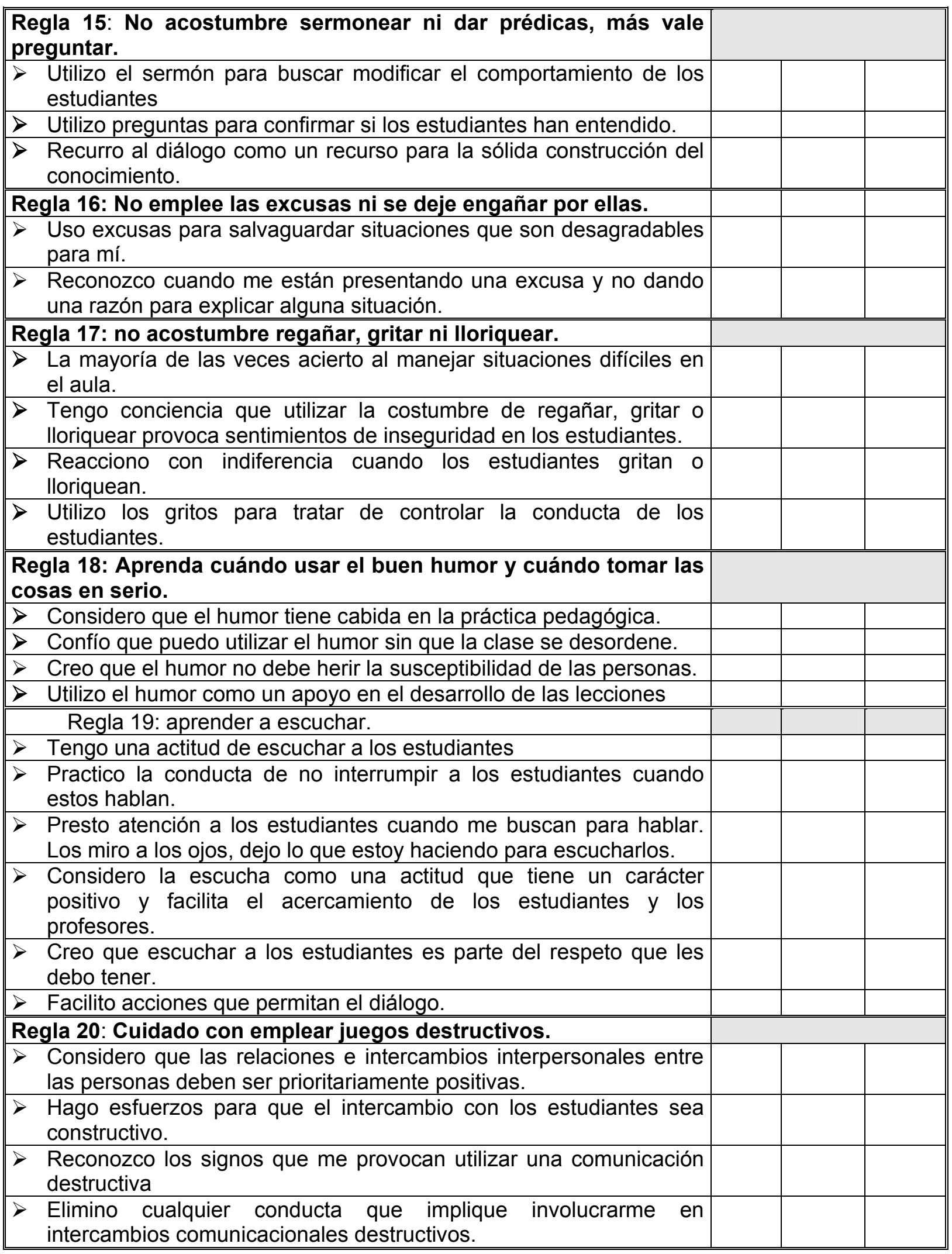




\section{A manera de conclusión}

Si no se siguen algunas de las reglas mencionadas como marco de la relación entre el maestro y los alumnos, se establece un estilo de comunicación destructivo entre las personas. La relación entre el maestro y el niño no es ajena a esto. Aprender a reconocer las señales o signos que el cuerpo envía y las sensaciones que producen y aprender a reconocerlas en los niños, son principios importantes para reflexionar sobre lo que está pasando con el proceso de comunicación.

Al llegar al final de este artículo, quizá esta autora descubrió, que lo más importante que desea comunicar, es que no todas las personas tienen que ser expertas en comunicación humana $y$, menos aún, ser perfectas en la utilización de la misma. Sin embargo, todas aquellas que están en contacto con los niños, tienen la innegable responsabilidad de dedicar tiempo a la reflexión sobre la conducta personal, de manera que la figura e imagen que perciban los niños sea clara y positiva y que tengan referencia de un modelo inspirador que sea digno de imitar. 


\section{Referencias}

Álvarez, A.; Valladares, B. (1987). Guía de orientación a padres en técnicas de comunicación con sus hijos. San José: Editorial de la Universidad de Costa Rica.

Becker, W. (1989). Los padres son maestros. Programa de manejo infantil. (2a ed.). México: Limusa.

Biehler, R. y Showman, J. (1990). Psicología Aplicada a la enseñanza. México: Limusa.

Charles, C.M. (1989). Building classroom discipline. ( $3^{a}$ ed.) New Cork: Longman Inc.

Cubero, C. Abarca, A.; Nieto, M. (1996). Percepción y manejo de la disciplina en el aula. San José, Costa Rica: IIMEC.

Curwin, R.; Mendler, A. (1983). La disciplina en clase. Guía para la organización de la escuela y el aula. Madrid: Narcea, S.A. de Editores.

Díaz-Barriga, F.; Hernández H. (1999). Estrategias docentes para un aprendizaje significativo. Una interpretación constructivista. México: Mc. Graw Hill.

Dobson, J. (1990). Atrévete a disciplinar. Florida: Editorial Vida.

Edwards, C. (1993). Discipline problems and their causes. En Classroom discipline and management. United States: Macmillan Publishing Company.

Englander-Golden, P. (1993). Comunicación Consigo Mismo, comunicación entre otros (say it stright). Costa Rica: Fundación Paniamor

Faben, A.; Mazlish, E. (1995). Cómo hablar para que los niños escuchen y cómo escuchar para que los niños hablen. México: Edivisión.

Fontana, D. (1997). La disciplina en el aula. Gestión y control. Argentina: Santillana.

Gallager, J. (s.f.). Métodos cualitativos para el estudio de la educación. Michigan State University. Documento de trabajo dado a conocer en el Instituto de Tecnología de Australia Occidental. Traducción de Corestanza C. Hazelwood y Judith Viveros, pp. 118.

García, N.; Rojas, M.; Brenes, M. (1994). Conocimiento, participación y cambio. Comportamientos en el aula. Costa Rica: Editorial de la Universidad de Costa Rica.

Janesick, V. (1989). Qualitative Research Methods: History, Foundation. Uses and Abuse. Facultad de Educación, Universidad de Costa Rica.

Lefrancois, G. (2001). El ciclo de la vida. México: International Thomson Editores.

León, A. (1998). El maestro y los niños. La humanización del aula. Costa Rica: Editorial de la Universidad de Costa Rica.

Papalia D.; Wendkos, S.; Suskin, R. (2001). Psicología del Desarrollo. Colombia: Mc. Graw Hill. 
Riquelme, N. (2000). Programa para la promoción de formas de disciplina efectiva y positiva. Costa Rica: Defensa de los Niños Internacional.

Shapiro, L. (1997). La inteligencia emocional de los niños. México: Sevilla Editores. S.A. de C.V.

Sprinhall, N.; Sprinhall R.; Oja, S. (1999). Psicología de la Educación. España: Mc. Graw Hill.

Stenhouse, L. (1974). La disciplina en la escuela. Orientaciones para la convivencia escolar. Buenos Aires: El Ateneo.

Vargas, A.; Orozco, H.; Martínez, C. (2000). Liderazgo, relaciones de poder y resolución de conflictos. Costa Rica: Ministerio de Educación Pública / Universidad de Costa Rica.

Wahlroos, S. (1978). La comunicación en la familia. Una guía hacia la salud emocional. México: Diana.

Watkins, C.; Wagner, P. (1991). La disciplina escolar. Propuesta de trabajo en el marco global del centro. Barcelona: Paidós lbérica.

Wielkiewicz, R. M. (1992). Manejo conductual en las escuelas. Principios y métodos. México: Limusa.

Woolfolk, A. (2000). Psicología de la Educación. México: Prentice Hall.

Yelon, S. L.; Weinstein, G. W. (1988). La psicología en el aula. México: Trillas. 